\title{
An Investigation of the Impact of Teaching Critical Thinking on the Iranian EFL Learners' Speaking Skill
}

\author{
Ali Malmir (Corresponding Author) \\ Allameh Tabataba'i University, Tehran, Iran \\ Email: a.malmir@yahoo.com \\ Samad Shoorcheh \\ Islamic Azad University, Maragheh Branch, Maragheh, Iran \\ Email: samad.shoorcheh@gmail.com
}

\begin{abstract}
This study has attempted to determine the effect of critical thinking on Iranian EFL learners' speaking ability. There were two equal-sized groups of 20 learners: a control group and an experimental one. The subjects were advanced EFL learners at Shokouh Language Institute in Hamedan, Iran. There were 10 male and 10 female learners in each group. In both groups, similar topics were proposed for group discussion such as air pollution, global warming, friendship, drug addiction, happiness, etc. In the experimental group, in addition to having discussion on the given issues, the teacher devoted some time for teaching critical thinking techniques during the class time. In the very first session, the teacher explicitly elaborated on what critical thinking processes are. Then, during the following sessions the teacher taught critical thinking techniques for about $\mathbf{2 0}$ minutes and gave learners time to practice these skills. The findings of the current study revealed that those students who received instruction on critical thinking strategies did better on the oral interview post-test. In addition, it was observed that within the experimental group there was not any significant difference between the performances of male vs. female Iranian EFL learners' speaking ability after giving the treatment.
\end{abstract}

Index Terms — critical thinking, English as a Foreign Language (EFL), speaking skill, problem-solving tasks

\section{INTRODUCTION}

Critical thinking is a very hotly debated topic these days. All educators are now aware of the importance of equipping learners' with critical thinking techniques, and teachers are making efforts to teach these techniques in the most appropriate way. Critical thinking is the intellectually disciplined process of actively and skillfully conceptualizing, applying, analyzing, synthesizing, and/or evaluating information gathered from, or generated by, observation, experience, reflection, reasoning, or communication, as a guide to belief and action (Sezer, 2008).

Children are not born with critical thinking skills. So how can we make critical thinkers out of children to succeed in their whole life? To start with, education could be the first step for promoting critical thinking among the children. Fisher and Scriven (1997) state critical thinking skills are required to be taught since students' thinking skills are not enough to face the problems students deal with either in education or in daily life. Therefore, educators are required to focus on teaching critical thinking to inform them how to learn instead of just transmitting information that is what to say. Emphasizing on making critical thinking as a part of educational courses, scholars have suggested that critical thinking can be taught in different classroom areas, such as those suggested by Shafersman(1991) including lectures, laboratories, writing activities, term papers, exam questions, home work, and quantitative exercises.

At each educational level, thinking must be practiced in each content field. This means hard work for the teacher. It's much easier to teach students to memorize facts and then assess them with multiple-choice tests. In a course that emphasizes thinking, objectives must include application and analysis, divergent thinking, and opportunities to organize ideas and support value judgments. When more teachers recognize that the facts they teach today will be replaced by the discoveries of tomorrow, the content-versus-process controversy may be resolved (Schmitt, 2002).

Nosich (2001) holds that most scholars believe that skills needed to begin to think about issues and problems do not suddenly appear in our students. Teachers who have attempted to incorporate higher level questioning in their discussions or have administered test items demanding some thought rather than just recall from their students are usually dismayed at the preliminary results. Unless the students have been prepared for the change in expectations, both the students and the teacher are likely to experience frustration.

Thus, we can conclude that critical thinking is quite complicated, and it is difficult for a child to develop such a complex ability without receiving aids from outside. Therefore, we understand that the task of teachers as people who play the pivotal role of training critical thinkers is very crucial, particularly in a language classroom in which students 
should get the opportunity to express themselves and evaluate the arguments of their peers. Up to this date, little is known about the importance of teaching critical thinking skills in language classroom. To eliminate this issue, the present study aims at investigating the effects of teaching these skills in a speaking classroom.

\section{LITERATURE REVIEW}

\section{A. Critical Thinking}

Over the past twenty years critical thinking has moved from a small corner of the stage in philosophy and the social sciences to front and center. Higher education writers agree that critical thinking should be included in the undergraduate curriculum. However, there seems to be little agreement on exactly what critical thinking is (Allen, Rubenfield, \& Scheffer, 2004).

A person who thinks critically employs the scientific method for understanding the ordinary world. This is true because critical thinking mimics the well-known method of scientific investigation: a question is identified, a hypothesis is formulated, relevant data are gathered, the hypothesis is logically tested and evaluated, and reliable conclusions are drawn from the result (Stapleton, 2002; Angeli \&Valanides, 2009). All of the skills of scientific investigations are matched by critical thinking, which is therefore nothing more than scientific method used in everyday life.

Wade (1995) identifies eight characteristics of critical thinkers: Critical thinkers involve in asking questions, defining a problem, examining evidence, analyzing assumptions and biases, avoiding emotional reasoning, avoiding oversimplification, considering other interpretations, and tolerating ambiguity. Dealing with ambiguity is also seen by Strohm and Baukus (1995) as an essential part of critical thinking, "Ambiguity and doubt serve a critical-thinking function and are a necessary and even a productive part of the process" (p. 56)

Peak (1997), Mishoe and Welch (2002), and Facione (2007) point out critical thinkers have got different attributes which makes no difference what definition you use for critical thinking. These features help us distinguish them from uncritical thinkers. Here are some of those characteristics of a critical thinker:

- Asks relevant questions to the issue

- Assesses arguments which are made

- Admits a lack of understanding

- Has a sense of curiosity

- Analyses the interpretations and claims made

- Analyses the problems

- Is eager on finding new solutions

- Is a careful listener and is able to give appropriate feedback

- Does not jump to conclusions before all the facts have been collected

- Looks for proof

- Rejects incorrect or irrelevant information

- Compares beliefs and opinions with facts that come against them

- Formulates the central ideas that are involved

According to Bracken, Brown, and Feng (2009) the importance of teaching critical thinking is nowadays obvious to all educators. CT is essential as a tool of inquiry. As such, CT is a liberating force in education and a powerful resource in one's personal and civic life. While not synonymous with good thinking, CT is a pervasive and self-rectifying human phenomenon.

Carroll (2005) asserts that the ideal critical thinker is habitually inquisitive, well-informed, trustful of reason, openminded, flexible, fair-minded in evaluation, honest in facing personal biases, prudent in making judgments, willing to reconsider, clear about issues, orderly in complex matters, diligent in seeking relevant information, reasonable in the selection of criteria, focused in inquiry, and persistent in seeking results which are as precise as the subject and the circumstances of inquiry permit. Thus, educating good critical thinkers means working toward this ideal. It combines developing CT skills with nurturing those dispositions which consistently yield useful insights and which are the basis of a rational and democratic society (Worrell \& Profetto-McGrath, 2007).

Fisher (2003) also emphasizes the significance of teaching critical thinking skills. He contends that critical thinking skills are required to be taught since students' thinking skills are not enough to face the problems students deal with either in education or in daily life. Therefore, educators are required to focus on teaching critical thinking to inform them how to learn instead of just transmitting information that is what to say.

Freely and Steinberg (2000) highlight the important role of debates, group discussions, and individual problem solving activities to enhance critical thinking in the students. They argue that debates improve critical thinking if the ideal opportunity is provided by the instructor for students. As far as it is a process of asking and answering questions and finding information to arrive at a reasoned judgment on a proposition, students have got the chance of coming against a theory. In that case, they not only increase their knowledge but also try to win a decision. Consequently, they greatly use their ability of critical thinking. "By setting group discussions, students are made to come up with a single decision through a collaborative activity analyzing others' beliefs, using the same standards and values of the members 
of the group, and taking the responsibility of supporting the group" (Freely \& Steinberg, 2000, p.9). As Wallace (2003) has claimed setting some sort of activities upon which individual decisions are made can promote critical thinking skills in students. It would be a kind of individual decision making while all the dimensions of a problem are controlled by the person without any further support. So that the person reflects on his own opinion, monitors himself, and makes the final decision on his own.

Some instructors might think that critical thinking cannot be taught through lecturing. Because these practitioners think that critical thinking is an active process whose skills such as analysis, synthesis, and reflection must be learned by performing them (Richards \& Schmidt, 2002; Cortell, 2005; Grosser \& Lombard, 2008). Thus, lecturing is considered as a passive activity when students just listen to the lectures passively. However, it is possible to make lectures active activities by stopping students while giving lectures and asking them some thoughtful questions about the materials which have been just presented.

Laboratories especially courses benefit a lot. The reason is obvious. Here, students practice their critical thinking. Because they are learning scientific method in which discovery learning is emphasized and clearly, critical thinking is involved in discovery learning when one tries to find relevant information and make inferences (Mangena \& Chabeli, 2005).

Writing activities are the best way to teach critical thinking. Because writing is an activity which forces students to organize their thoughts, think deeply about their topic and present their conclusions in a persuasive manner. Goatly (2000) states that one reason that we might expect writing to improve critical thinking is the existence of some sort of writing such as persuasive or argumentative writing which have been difficult for the students.

\section{B. Speaking Skill}

Also the communicative activities which are used in the CL T class should be based on authentic materials which have been written for the real world use. Such materials are claimed to give students opportunities to develop strategies for understanding language as it is actually used. Furthermore, communicative activities are often carried out by the students in small groups. The nature of Speaking is so much part of daily life that we take it for granted. However, learning speaking, whether in a first or other language, involves developing subtle and detailed knowledge about why, how and when to communicate, and complex skills for producing and managing interaction, such as asking a question or obtaining a turn. According to Brown (2002), walking and talking are "species specific".

Speaking skills are often considered the most important part of an EFL course. With the growing need for international communication in the information age, many language learners attend language classes to improve their speaking ability. Even though many students have mastered basic speaking skills, some students are much more effective in their oral communication than others. And those who are more effective communicators experience more success in school and in other areas of their lives. According to Folse (2006), for most people, the ability to speak a language is synonymous with knowing that language since speech is the most basic means of human communication. Nevertheless, speaking in a second or foreign language has often been viewed as the most demanding of the four language skills. Speaking a language is especially difficult for foreign language learners because effective oral communication requires the ability to use the language appropriately in social interactions. Diversity in interaction involves not only verbal communication, but also paralinguistic elements of speech such as pitch, stress, and intonation (Seligson, 1997; Fulcher, 2003).

Based on Thornbury (2007) spoken interaction involves producing and negotiating language rather differently from the way it is used in writing. Speakers and listeners are simultaneously involved in both producing and processing spoken interactions. They are under time constraints which means that they must process language as they go, with no opportunities to go back and make changes. Speakers must also take account of relationships with others, adjusting their language according to the meanings they wish to get across, and responding to verbal or non-verbal signals from their listeners. Many spoken interactions consist of commenting on immediate actions or events, or casually moving from one topic to another (Celce-Murcia, 2001; Richard, \& Renandya, 2002).

As far as assessing speaking is concerned, Joiner and Jones (2003) contend that among the macro skills of language, it has been widely recognized that speaking, particularly in a second or foreign language, is the most difficult language skill to assess. The method used for assessing oral communication skills depends on the purpose of the assessment. According to Luoma (2004) two methods are used for assessing speaking skills. In the observational approach, the student's behavior is observed and assessed unobtrusively. In the structured approach, the student is asked to perform one or more specific oral communication tasks. His or her performance on the task is then evaluated. The task can be administered in a one-on-one setting -- with the test administrator and one student -- or in a group or class setting. In the present study we adopted a structured approach for interviewing each learner individually at the end of the course. Both observational and structured approaches use a variety of rating systems. A holistic rating captures a general impression of the student's performance. A primary trait score assesses the student's ability to achieve a specific communication purpose - for example, to persuade the listener to adopt a certain point of view. Analytic scales capture the student's performance on various aspects of communication, such as delivery, organization, content, and language. Rating systems may describe varying degrees of competence along a scale or may indicate the presence or absence of a characteristic (Luoma, 2004). 
Critical thinking has gained widespread popularity in various disciplines nowadays. Educators have realized the importance of nurturing students who are critical thinkers and have a critical eye to look at the world surrounding them. Critical thinking skills figure prominently among the goals for education, whether one asks developers of curricula, educational researchers, parents, or employers. Although lots of studies have been conducted in various fields to examine the significance of critical thinking and the methods of teaching it, we don't know much about the relationship between critical thinking and language learning. In other words, our knowledge about the effects of explicit instruction of critical thinking skills on language learning ability is far from perfect. To shed more light on this issue, the researchers embarked on the task of investigating the impact of teaching critical thinking skills on EFL learners' speaking ability.

\section{Research Questions}

This research has two main research questions:

$\boldsymbol{Q}_{\boldsymbol{l}}$. Does teaching critical thinking skills have any significant effect on the development of speaking ability of Iranian EFL learners?

$\boldsymbol{Q}_{2}$. Do teaching critical thinking skills affect male and female learners differently?

\section{Null Hypotheses}

Based on the above research questions the following null hypotheses are formulated:

$\boldsymbol{H O}_{\boldsymbol{1}}$. Teaching critical thinking skills has no significant effect on the speaking ability of Iranian EFL learners.

$\boldsymbol{H O}_{2}$. Teaching critical thinking skills do not affect male and female language learners differently.

\section{Methodology}

\section{A. Participants}

The participants of the present study were 40 advanced English learners studying at Shokouh Language Institute in Hamedan. They had already passed 12 courses in English and were at very advanced levels of English proficiency. They attended a free discussion class in which different issues ranging from social to environmental topics were discussed. There were both male and female learners in class. The learners were between 15 and 24 years of age. The participants were randomly assigned to control and experimental groups, each group consisting of 20 people. There were 10 male and 10 female learners in each group.

\section{B. Instrumentation and Data Collection}

\section{TOEFL}

In order to achieve homogeneity between the subjects regarding their general English proficiency, a TOEFL test was administered at the beginning of the study.

II. Oral interviews as pre-test, post-test

This research project exploited oral interviews both prior to the beginning of the conversational course and also right after the end of the course like pre-test and post-test. Subjects in both control and experimental groups were interviewed orally prior to the beginning of the conversational course. All subjects were asked the same questions by their own teacher. The interviews were recorded for further detailed, analytic scorning. Each taped-interview was rated by two raters in order to ensure the inter-rater reliability of the assessments. The first interviews were carried out prior to the beginning of the course to be compared with those conducted at the end of the course. Subjects in both groups had already passed nine terms of English language conversation; they were thought to form two almost-homogeneous classes. The second interviews which were conducted at the end of the conversational course were to determine how much of a difference the treatment given to the experimental group, made in comparison with the control group which did not receive such a treatment. The results of the first interviews which were assessed by two raters, then compared with those of the second interviews to see whether the treatment given to the experimental group, had any impact upon their oral proficiency level in comparison with subjects in the control group who had no such treatment.

\section{How were the interviews conducted?}

The first interviews which were conducted prior to the beginning of the course consisted of the following questions?

1. Tell me about yourself and your family?

2. Tell me about your own neighborhood. What is important to you in a neighborhood?

3. What are three main reasons of divorce in our country? What are to be done to decrease divorce rate?

4. Name four things you would like to do, but you can't.

The second interviews which were conducted right at the end of the term consisted of the following questions?

1. What is the most memorable experience of your life? Why so?

2. What kind of a person are you from your own perspective? What are your positive and negative points?

3. Describe your own hometown. Can you compare it with the capital city, what are the similarities and differences?

4. What are the pros and cons of our own culture?

\section{The rating scale (Luoma.2004)}

A checklist was developed according to which the raters were able to make more valid, reliable, and consistent assessment. Here I was not interested in a psychometric kind of assessment which is more limiting, rigorous, and scientific. What I was really looking for, was a more dynamic and flexible approach to assessment. The approach 
adopted, was more likely to resemble performance or alternative assessment which allowed for more flexibility and also more freedom. The checklist was developed from an analytic descriptors of spoken language (council of Europe, 2001 cited in Luoma,2004, pp.72-74). The items on the list were accuracy, fluency, range, coherence, and interaction. Level descriptors $(\mathrm{A}+, \mathrm{A}, \mathrm{B}+, \mathrm{B}, \mathrm{C}+$, and $\mathrm{C})$ were specified for each item on the checklist according to which the raters assigned scores to the interviewees.

\section{1). Accuracy:}

$A+$ : consistent grammatical control of complex language

$A$ : a high degree of grammatical accuracy, errors are rare, difficult to spot and generally corrected when they do occur.

$B+$ : a relatively high degree of grammatical control; makes no global errors which block communication and can correct most of the mistakes pointed to him.

$B$ : uses accurately a repertoire of frequently used routines and patterns associated with more predictable situations.

$C+$ : uses more simple structures correctly, but still systematically makes basic mistakes

$C$ : only limited control of a few grammatical structures and sentences patterns in a memorized repertoire.

\section{2). Fluency:}

$A+$ : can express himself or herself spontaneously at length with a natural colloquial flow, avoiding or backtracking around any difficulty that the interlocutor is hardly aware of.

$A$ : can express himself or herself fluently and spontaneously, almost effortlessly. Only a conceptually difficult subject can hinder a natural, smooth flow of language.

$B+$ : can produce stretches of language with fairly even tempo: although he or she can be hesitant as he or she searches for patterns and expressions. There are a few noticeably long pauses.

$B$ : can keep going comprehensibly, even though pausing for grammatical and lexical planning and repair is very evident, especially in longer stretches of free production.

$C+$ : can make himself understood in very short utterances, even though pauses, false starts, and reformulations are very evident.

$C$ : can manage very short, isolated, mainly pre-packaged utterances, with much pausing to search for expressions.

\section{3). Range:}

$A+$ : great flexibility in reformulating ideas with different linguistic forms to convey meaning, to emphasize, to differentiate, and to eliminate ambiguity. And also has a good command of idiomatic expressions and colloquialisms.

$A$ : has a good command of a broad range of linguistic items to express himself or to reformulate ideas in an appropriate style on a wide range of general, academic, professional or leisure topics without having to restrict what he has to say.

$B+$ : has a sufficient range of language to be able to give clear descriptions and express viewpoints on most general topics without much conspicuous searching for words.

$B$ : has enough language to get by, with sufficient vocabulary to express himself with some hesitation and circumlocution on topics such as family, hobbies, work, travel, and current events.

$C+$ : uses basic sentence patterns with memorized phrases to communicate limited information in simple everyday situations.

$C$ : has a very basic repertoire of words and simple phrases related to personal details and particular concrete situations.

\section{4). Coherence:}

$A+$ : can create coherent and cohesive discourse marking, full and appropriate use of a variety of organizational patterns and a wide range of connectors and other cohesive devices.

$A$ : can produce clear, smoothly-flowing, and well-structured speech. Shows controlled use of organizational patterns, connectors, and cohesive devices.

$B+$ : can use a limited number of cohesive devices to link his utterances into clear coherent discourse.

$B$ : can link a series of shorter, discrete, and simple elements into a connected, linear sequence of points.

$C+$ : can link groups of words with simple connectors like 'and', 'but', and 'because'.

$C$ : can link words or group of words with very basic linear connectors like 'then' or 'and'.

\section{5). Interaction:}

$A+$ : can interact with ease and skill, picking up and using non-verbal and intonational cues apparently effortlessly. Can interweave his contribution into the joint discourse with fully natural turn-taking, referencing, and allusion-making (16-20 scores).

A: can select a suitable phrase from a readily rage of discourse functions to preface his remarks in order to keep or to get the floor and to relate his own contributions skillfully to those of other speakers (14 - 16 scores).

$B+$ : can initiate discourse, take his turn when appropriate and end conversation when he needs to. Can help the discussion along on familiar ground confirming comprehension, inviting others in, etc. (11-15 scores).

$B$ : can initiate, maintain, and close simple face-to-face conversations on topics that are familiar or of personal interest. Can repeat back what someone has said to confirm mutual understanding? (8-11 scores). 
$C+$ : can answer questions and respond to simple statements. Can indicate when he is following but is rarely able to understand enough to keep conversation going on his own record (4- 8 scores).

$C$ : can ask and answer questions about personal details. Can interact in simple way but communication is totally dependent upon repetition, rephrasing, and repair (0-4 scores).

Each subject was given a score based on the previously-mentioned descriptions and the level descriptors specified on the checklist. The maximum score in this scale is $74(20+16+15+11+8+4)$ for each item and accordingly the total score is the average of all items divided by the number of items (again the total score can be as high as 74).

\section{Procedure}

Forty language learners taking a free discussion class at Shokouh Language Institute in Hamedan were selected and randomly assigned to control and experimental groups. In fact, the stratified sampling technique was used for the selection of subjects because the current study needed both male and female subjects. Accordingly, 20 male students and 20 female students were selected from among those advanced students who studied at Shokouh Language Institute in Hamedan. In order to ensure that learners were homogenous in terms of their linguistic ability, a paper-based TOEFL test was administered to learners at the beginning of the semester. The course consisted of 15 sessions, each lasting one and a half hours. An instructor taught the experimental group (G1) and another teacher taught the control group (G2). In both groups, similar topics were proposed for group discussion such as air pollution, global warming, friendship, drug addiction, happiness, etc. The teacher played the role of a discussion leader who tried to make sure everyone got the opportunity to express his/her opinions on proposed topics. The students were required to read on the topic before coming to the class and be ready for discussing their views on suggested topics. In the experimental class, in addition to having discussion on the given issues, the teacher devoted some time for teaching critical thinking techniques during the class time. In the very first session, the teacher explicitly explained what critical thinking is and how significant it is to have a critical mind in modern life. Then, during the following sessions the teacher taught critical thinking techniques for about 20 minutes and gave them time to practice these skills. These skills include involving learners in problem solving activities, raising questions, teaching logical reasoning, evaluating others' arguments, etc. Everything was the same for the control and experimental group except for the treatment.

\section{RESULTS AND DisCUSSIONS}

Seventy Iranian EFL students studying English Language at Shokouh Language Institute in Hamedan were selected. These learners were given a TOEFL test. Then the gathered data were analyzed by the SPSS program. The descriptive statistics revealed that the minimum score was 380 and the maximum score was as high as 610 . The mean score was 580.64 with a standard deviation of 80.20. Then 40 top students were selected based on their scores on the TOEFL test. Actually, because the researcher needed two equal groups of 20 he selected the top 40 students whose scores was around the mean and above the mean. There were 10 male and 10 female learners in the each group. Therefore the researcher used stratified sampling for creating these two homogeneous groups.

Subjects in both control and experimental groups were interviewed orally prior to the beginning of the conversational course. All subjects were asked the same questions by their own teacher. The interviews were recorded for further detailed, analytic scorning. Each taped-interview was rated by two raters in order to ensure the inter-rater reliability of the assessments. Then all of the papers were rated by two raters based on Luoma (2004) profile for assessing speaking.

As it was mentioned above two raters rated the oral interviews by the students at the pre-test. So there were two scores for each learner at the oral interview pre-test. Accordingly, in order to see if there is a high degree of gotogetherness between the scores given by two raters, the Pearson Product-Moment Correlation was used and a correlation coefficient of .826 was obtained. Since 20 oral interviews were scored by the two scorers, the degree of freedom is 18. The critical values for $r$ at the .05 and .01 levels of significance are .443 and .561 respectively. Because the obtained value for $r$ was greater than the critical values for $r$ with 18 degrees of freedom (DF= 18) both at .05 and at .01 levels of significance $(\mathrm{F}>.443$ and $\mathrm{F}>.561)$, it was concluded that there was a high positive correlation between the ratings of the two scorers.

After the treatment, needed data was gathered and analyzed using SPSS. The descriptive statistics for performances of the two groups on the pre-test and posttest have been given in Table 1. Figure 1 below depicts the results in a vivid manner. In order to see if there was any significant difference between the two groups at the outset an independent t-test was used. The results for the used independent T-test can be seen in the Table 3. Then the results of pretest and posttest for each group were compared using matched t-tests (See Table 2). It was observed that the two groups have had improved their speaking skills during the study.

\section{A. Answering the First Research Question}

The main question of the current study is to check if critical thinking has been more in teaching speaking to Iranian EFL learners i.e. whether subjects in experimental group (G1) who have received critical thinking training and practicing have outperformed subjects in control group (G2). As you can see in Table 1 the mean score for the Experimental Group is 67.16 and the mean score for the Control group on the post-test is 59.80. So there is an apparent difference between the performances of the two groups on the post-test in favor of the experimental group. But in order 
to check if such a difference is statistically significant or not an independent T-test was used. There results of the used independent test have been presented in the table 2. The obtained t value is 4.27. This value is greater than the critical value for $t$ with 38 degrees of freedom at .05 level of significance. Therefore the first null hypothesis of the study can be rejected and it can be concluded that the experimental group has outperformed the control group. Accordingly, it can be concluded that teaching critical thinking strategies has been effective in the development of Iranian EFL learners' speaking skill.

\section{B. Answering the Second Research Question}

The second research question of the present study was "Does teaching critical thinking skills affect male and female learners' speaking ability differently?" In order to answer this question the results for the performances of female and male Iranian EFL learners in the experimental group were compared with each other using an independent $\mathrm{T}$-test. The descriptive statistics for performance of male vs. female students have been given in table 4 .

As you can see the mean score for females is 68.52 and the mean score for males on the post-test is 65.80 . So there is an apparent difference between the performances of the two groups on the post-test in favor of the females. But in order to check if such a difference is statistically significant or not, an independent T-test was used (Table 3). As you can see the calculated value for $t$ at .05 level of significance 18 degrees of freedom is 1.07 . Because this value is less than the critical value for $t$, the second null hypothesis of the study is not rejected and it can be said that there is not any significant difference between the performances of males vs. females on the posttest. This means that although there is a difference in favor of females, teaching critical thinking has almost had the same impact on the speaking skill of the two subgroups within the experimental group.

\section{CONCLUSIONS AND IMPLICATIONS}

The findings of the current study revealed that experimental group outperformed the control group on the post-test. That is the students who received instruction on critical thinking strategies did better on the oral interview post-test. Of course both groups showed improvements in their speaking skills in comparison with their status at the beginning of the study. Namely both groups speaking improved irrespective of the methodology for teaching speaking. But there was a significant difference between the performances of the two groups after the special treatment was given to the experimental group. So it was concluded that critical thinking training had a crucial impact on promoting speaking ability of Iranian EFL learners. In addition, the proceedings of the present study showed that within the experimental group there was not any significant difference between the performances of male vs. female Iranian EFL learners' speaking ability. Now the question is that how can we justify for this kind of conclusions? Is critical thinking instruction really effective in development of EFL speaking ability? If so what are the strong points and advantages of teaching critical thinking strategies that helped students develop better speaking abilities?

It should be said that this kind of result is quite natural because both groups received a treatment of 15 sessions. Therefore it is natural that even the control group in which the learners didn't receive critical thinking instruction showed a progress in comparison with their status at the outset. Anyway in control group the students were active in the class, they talked to each other, they did role-plays, they learned many things to develop their speaking ability from the teacher and from their classmates during a long period of 15 sessions. So this progress from the pretest to the post-test for the subjects in the control group is definitely something justifiable as it is true for the experimental group.

But in the main question of the current study is why experimental group outperformed the control group on the posttest? In order to answer this crucial question we should consider the characteristics of critical thinking instruction and we should probe this kind of instruction closely to see what are the strong points, advantages, helpful facets and practical aspects in fostering EFL speaking.

In the experimental group, in addition to having discussion on the given issues initiated by the teacher and sometimes by the students themselves, the teacher allocated some time for teaching critical thinking techniques during the class time. Dialogue-focusing strategies such as identifying direction, sorting ideas for relevance, and focusing on key points are very important critical thinking strategies which were practiced in the classroom. These techniques are handy if the dialogue loses direction, becomes too wordy, or becomes so dense that learners simply must do some sorting or unpacking of ideas. Such "intellectual clean-up" — which involves putting things in order and making key issues prominent - is necessary in any dialogue. Critical-thinking strategies that helped the students in the current study include full-spectrum questioning, making connections, and honoring multiple perspectives. With these tools, the participants could add a deeper dimension to a dialogue that is "wallowing in the shallows" of a satisfactory, conventional approach or an unexamined vocabulary.

Critical thinking techniques helped the learners to uses evidence skillfully and impartially in their interactions with their classmates during the treatment. Such kind of techniques motivated the learners to organize their thoughts and to articulate them concisely and coherently in their oral productions. But the students in the control group didn't enjoy the benefits of such powerful strategies. Furthermore, in the experimental group the implementation of critical teaching strategies were very effective to guide the students to distinguish between logically valid and invalid inferences when they were talking to the teacher or to the peers. 
Critical-thinking strategies helped the learners to become active participants in the interaction process by listening carefully to other students lectures, by judging on those utterances, and by making the best decisions about what to say in response to what has been said in the conversation by other interactants. In fact, critical thinking strategies help the learners consider all the characteristics of a good conversation when they were talking in the classroom. The students were totally attentive to what other students said and to what themselves wanted to say in the interactions.

A highly important aspect in the experimental class was that critical thinking strategies were quite suitable for a cooperative classroom. And cooperate learning in turn can facilitate critical thinking and can foster critical thinking abilities of the language learners. This idea is a very important one which has been studied in many investigations. For example Cooper (1995) argues that putting students in group learning situations is the best way to foster critical thinking. "In properly structured cooperative learning environments, students perform more actively benefiting from critical thinking with continuous support and feedback from other students and the teacher" (p. 8). So cooperative learning directly and indirectly enhances critical thinking and speaking ability of language learners.

So the outperformance of the experimental group of learners on the post-test and after giving the special treatment in comparison with the control group which didn't receive this kind of treatment can be justified by the strong characteristics of critical thinking instruction which could help the students develop their EFL speaking ability and which could motivate them to speak more and accordingly to learn more in the classroom. Another finding of the current study was that female subjects in the experimental group did better than the male subjects but this kind of difference was not statistically significant. Therefore no clear and robust conclusion can be drawn about the superiority of female Iranian EFL subjects in using critical thinking strategies for developing their speaking ability compared with male learners. More research is needed to examine if gender plays any effective role in using critical thinking strategies for language learning in general and for developing EFL speaking ability in particular.

The prominent pedagogical implications in this research correspond with what the following scholar believes in. Worrell and Profetto-McGrath (2007) asserted that applying and using critical thinking activities with different levels of language proficiency in English language classrooms can increase learner's level of thinking and simultaneously can help language learners promote their speaking abilities and enhance their own judgmental power in authentic and realworld conversations. Critical thinking techniques can equip learners with instruments which help them to go beyond the surface information presented in the conversation by other participants and to make their own decisions when they want to talk and to enhance their speaking abilities in long turn. The findings of the current study indicate that a critical thinker is a better language learner. Because a person who thinks critically can ask appropriate questions, can activate relevant information, efficiently and creatively sort through this information, reason logically from this information, and come to reliable and trustworthy conclusions about what other people have said that helps him to arrange what he wants to say in the best way.

This study wants to emphasize that critical thinking and speaking are interrelated and interdependent. This claim is not the researchers claim in this study but it is a very profound and a research-based idea. Vygotsky (1962) has talked about the interdependence of thought and speech and has emphasized that it is thinking that motivates speaking and vice versa. And as you know thinking is not limited just to the speaking ability and other language skills are all based on thinking. Listening comprehension, reading, and writing are all rooted in the thinking processes. In fact, thinking is the hidden software of all cognitive activities. Accordingly, enhancing critical thinking strategies can directly lead to learning a language better. Thus language teachers should try to include the explicit instruction of critical thinking strategies in the classrooms.

As it was mentioned above, the good results of critical thinking strategies instruction are not limited to the speaking ability and they are helpful for other language skills. Thus the researchers of the study think that further research is needed to investigate the impact of teaching critical thinking on the other language skills and sub-skills like listening comprehension, reading comprehension, writing, vocabulary and grammar. Furthermore, the effect of implicit vs. explicit teaching of critical thinking strategies on EFL learners' different language skills and sub-skills needs more research.

\section{APPENDIX TABLES}

TABLE 1.

DESCRIPTIVE STATISTICS FOR PERFORMANCES OF THE TWO GROUPS ON PRE-TEST AND POST-TEST

\begin{tabular}{|c|l|l|l|l|l|l|}
\hline & & \multicolumn{3}{|l|}{ Pre-test } & Post-test \\
\hline Group & Treatment & $\mathrm{N}$ & Mean & SD & Mean & SD \\
\hline G1 & Experimental & 20 & 51.23 & 8.21 & 67.16 & 8.27 \\
G2 & Control & 20 & 51.20 & 7.80 & 59.80 & 10.85 \\
\hline
\end{tabular}

TABLE 2.

THE USED MATCHED T-TESTS

\begin{tabular}{|l|l|l|l|}
\hline Pair & $\mathrm{df}$ & $\mathrm{t}$ & $\mathrm{Sig}$ \\
\hline G1 Pretest/Posttest & 19 & 6.76 & $.000^{*}$ \\
G2 Pretest/Posttest & 19 & 3.16 & $.000^{*}$ \\
\hline \multicolumn{4}{|c}{$\left(\mathrm{P}<.05^{*}\right)$}
\end{tabular}


TABLE 3.

DESCRIPTIVE STATISTICS FOR PERFORMANCES OF THE MALES AND FEMALES ON PRE-TEST AND POST-TEST

\begin{tabular}{|l|l|l|l|l|}
\hline \multicolumn{4}{|l|}{} & Post-test \\
\hline Group & Gender & $\mathrm{N}$ & Mean & SD \\
\hline G1 & Female & 10 & 68.52 & 6.27 \\
& Male & 10 & 65.80 & 5.85 \\
\hline
\end{tabular}

TABLE 4

THE USED INDEPENDENT T-TESTS

\begin{tabular}{|l|l|l|l|}
\hline & df & t & Sig(2-tailed) \\
\hline G1- G2 Pretest & 38 & 0.686 & $.002^{*}$ \\
G1- G2 Posttest & 38 & 4.27 & $.189^{*}$ \\
G1- G1 Posttest & 19 & 1.07 & .386 (Male / Female) \\
\hline
\end{tabular}

$(\mathrm{P}<.05 *)$

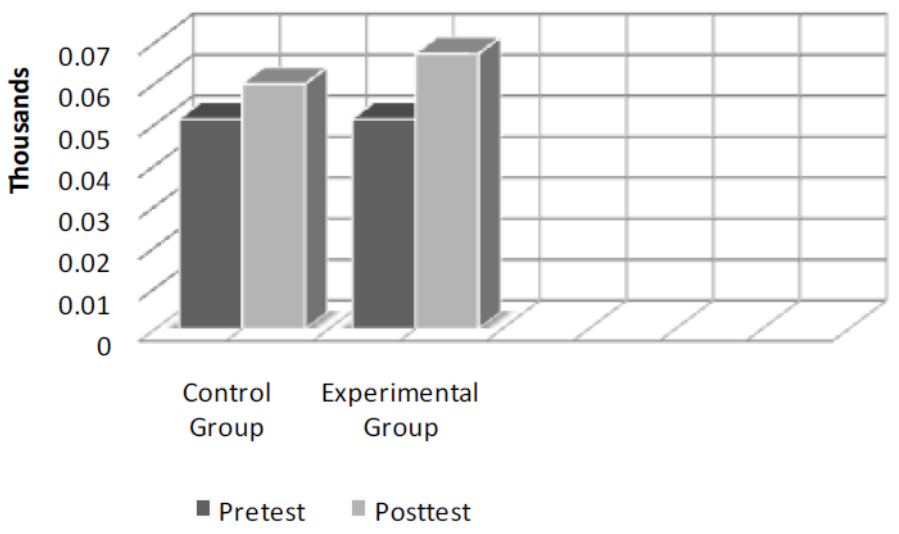

Figure 1 Pre-test \& Posttest Performances of Study Groups

\section{REFERENCES}

[1] Allen, G.D., Rubenfield, M.G., \& Scheffer, B.K. (2004).Reliability of assessment of critical thinking. Journal of Professional Nursing, Vol 20, No 1, pp 15-22.

[2] Angeli, C., \&Valanides , N. (2009) . Instructional effects on critical thinking: Performance on ill-defined issues. Learning and Instruction ,19 (2), pp. 322-334.

[3] Bracken .B, Brown, E., \& Feng, A.(2009).Critical thinking instruction. Journal for the Education of the Gifted. Vol. 33( 1), pp. 7-37.

[4] Brown, H. D. (2002). An interactive approach to language pedagogy. (2rd ed). White plains, NY: Pearson Production.

[5] Carroll, R. T. (2005). Teaching critical thinking. The Amazing Meeting in Las Vegas. McGrawhill.

[6] Celce-Murcia, M.(2001). Teaching English as a second or foreign language. (3rd ed). Los Angeles: Heinle \& Heinle.

[7] Chrisman, R. (1999).Testing speaking. TEFL China. Retrieved May 12th, 2011, from http://teflchina.org/teach/speak/.

[8] Cortell, S. (2005). Critical thinking skills: Developing effective analysis and argument. New York: Palgrave Macmillan.

[9] Cooper, J. L. (1995). Cooperative learning and critical thinking. Teaching of Psychology, 22(1), 7-8.

[10] Facione, P. A. (2007). Critical thinking: What it is and what it counts. Retrieved February 26, 2008, from http://www.controlz.com/storage/what is-ct.pdf .

[11] Fisher, A. (2003). An introduction to critical thinking. Mahwan, NJ: Lawrence Erlbaum. Retrieved February 26, 2008, from www.amazon.com/critical thinking-Alec- Fisher/dp/0521100984 .

[12] Fisher, A., \& Scriven, M. (1997). Critical thinking: Its definition and assessment. CA: Edgepress.

[13] Folse, Keith. (2006). The art of teaching speaking. Michigan: Michigan University Press.

[14] Freely, A. J., \& Steinberg, D. L. (2000). Argumentation and debate: Critical thinking for reasoned decision making. Belmont, CA.

[15] Fulcher, G. (2003). Testing second language speaking. New York: Pearson Longman.

[16] Goatly, A. (2000). Critical reading and writing. London: English Route.

[17] Grosser, B., \& Lombard, J.J.(2008). The relationship between culture and the development of critical thinking abilities of prospective teachers. Teaching and Teacher Education 24, (3),pp. 1364-1375.

[18] Joiner, R., \& Jones, S. (2003). The effects of communication medium on argumentation and the development of critical thinking. International Journal of Educational Research, 23 (4), pp. 39 861-871.

[19] Luoma, S. (2004). Assessing speaking. New York, Cambridge University Press.

[20] Mangena ,A., \& Chabeli , M.M. (2005). Strategies to overcome obstacles in the facilitation of critical thinking in nursing education. Nurse Education Today 25, 291-298.

[21] Mishoe, S. C., \& Welch, M. A., Jr. (2002). Critical thinking in respiratory care: A problem-based learning approach. New York: McGraw-Hil. 
[22] Nosich, G. (2001). Learning to think things through: A guide to critical thinking in the curriculum. Upper Saddle River, NJ: Prentice-Hall.

[23] Peak, F. S. (1997). Attributes of critical thinking. Retrieved March 12, 2008, from //www.accd.edu/sac/history/keller/Accditg/ssct.htm.

[24] Richards, J.C. \& Schmidt, R. (2002). Longman dictionary of language teaching and applied linguistics. London: Pearson Education

[25] Richard, J. c.,\& Renandya, W. A.(2002). Methodology in language teaching. Cambridge: Cambridge University Press.

[26] Schafersman, S. D. (1991). An introduction to critical thinking, Retrieved March http://www.freeinquiry.com/criticalthinking.html.

[27] Schmitt, n.(2002). An introduction to applied linguistics. Oxford: Oxford University Press.

[28] Seligson, P. (1997). Helping students to speak. Richmond Publishing.

[29] Sezer, R.( 2008).Integration of critical thinking skills into elementary school teacher. Education; 128(3), pp. 349-363.

[30] Stapleton P. (2002) .Critical thinking in Japanese L2 writing: rethinking tired Constructs. ELT Journal Volume 56/3,pp. 123143.

[31] Strohm, S. M., \& Baukus, R. A. (1995). Strategies for fostering critical thinking skills. Journalism and Mass Communication Educator, 50 (1), 55-62.

[32] Thornbury, S. (2007). How to teach speaking. Pearson Longman.

[33] Wade, C. (1995). Using writing to develop and assess critical thinking. Teaching of Psychology, 22(1), 24-28.

[34] Wallace, C. (2003). Critical reading in language education. Palgrave Macmillan.

[35] Worrell, J.A., \& Profetto-McGrath, J. (2007). Critical thinking as an outcome of context-based learning among post RN students: A literature review. Nurse Education Today 27, 420-426.

Ali Malmir is a PhD candidate of TEFL at Allameh Tabataba'i University, Tehran, Iran. He got his M.A. in TEFL from Allameh Tabataba'i University in 2008. His research interests include Task-based Language Teaching, Discourse Analysis (DA), Interlanguage Pragmatics, and Language Assessment.

Samad Shoorcheh has M.A. degree of TEFL (Teaching English as a Foreign Language). Currently, he teaches English at Iranian university and colleges. He has also published three books for TEFL. He is interested in Applied Linguistics, Language Testing and Critical Pedagogy. 